Estudios Constitucionales, Año 17, № 1, 2019, pp. 233-264

ISSN 07180195

Centro de Estudios Constitucionales de Chile Universidad de Talca

"Tutela de la intimidad genética en Chile.

Una evaluación desde el estándar ofrecido por los derechos internacional y comunitario”

Luis Iván Díaz García - Kevin Alberto Ritz Parra

\title{
TUTELA DE LA INTIMIDAD GENÉTICA EN CHILE. UNA EVALUACIÓN DESDE EL ESTÁNDAR OFRECIDO POR LOS DERECHOS INTERNACIONAL Y COMUNITARIO*
}

\author{
Genetic Privacy PROTECTION In Chile. An EVAlUation From \\ STANDARD OFFERED BY INTERNATIONAL LAW AND BY THE EUROPEAN \\ UNION COMMUNITARIAN LAW
}

\author{
LUIS IVÁn Díaz García* \\ ivandiaz@uct.cl \\ Kevin Alberto Ritz Parra** \\ kevin.a.ritz@gmail.com \\ Universidad Católica de Temuco
}

RESUMEN: La presente investigación contrasta la regulación ofrecida por el derecho chileno para la tutela del derecho a la intimidad genética con el estándar ofrecido por el derecho internacional y por el derecho comunitario de la Unión Europea. Esta comparación permite evidenciar las omisiones y deficiencias de la regulación nacional y, por tanto, la urgente necesidad de contar con una legislación que le otorgue una robusta protección, tanto por su jerarquía iusfundamental como porque favorece a personas, familias y colectivos.

ABSTRACT: This research compares the regulation offered by the Chilean legal system for genetic privacy protection with the standard offered by International Law and by the European Union communitarian law. This comparison allows us to evidence national regulation omissions and failures and, therefore, the urgent necessity of having legislation that gives a robust protection, both for its iusfundamental hierarchy and for favoring people, families and groups.

PALABRAS CLAVE: Intimidad genética, Información genética, Vida privada, Intimidad - Derechos fundamentales.

KEY WORDS: Genetic Privacy, Genetic Information, Private Life, Privacy, Fundamental Rights.

\footnotetext{
* Trabajo recibido el 31 de julio de 2018 y aprobado el 10 de abril de 2019.

** Académico de la Facultad de Ciencias Jurídicas de la Universidad Católica de Temuco. Doctor en Derecho por la Universidad Carlos III de Madrid, España. Abogado por la Pontificia Universidad Católica de Chile.

*** Magíster en Derecho, con especialización en Derecho Público, por la Universidad Católica de Temuco, y abogado por la misma universidad.
} 


\section{INTRODUCCIÓN}

El avance científico ha permitido la obtención de un enorme número de información genética a partir de casi cualquier evidencia biológica: manchas de sangre, cabellos, restos óseos o de semen, etcétera ${ }^{1}$. Esta información genética permite detectar enfermedades, predisposiciones genéticas e incluso antecedentes hoy desconocidos, relativos no solo al sujeto del cual se han obtenido las muestras, sino también a su descendencia. De esta manera, se puede determinar "si una persona heredó un gen causante de una enfermedad antes de que se hayan manifestado los síntomas de esta"2, y hallar predisposiciones genéticas, "que informan sobre el mayor riesgo de desarrollar una enfermedad en particular, pero sin asegurar que la misma se desarrolle"3.

Los evidentes riesgos de segregación, exclusión o estigmatización de personas, familias o colectivos a partir del uso de esta información son elevados. Por otra parte, la información genética puede ser importante desde el punto de vista cultural para las personas o los grupos ${ }^{4}$. Al mismo tiempo, el sujeto se encuentra en indefensión desde que no es fácil que se percate de que su información genética ha sido obtenida sin su consentimiento, lo que significa que difícilmente pueda reaccionar contra dicha lesión 5 . Con la finalidad de evitar aquellos riesgos y esta indefensión, todo ordenamiento jurídico en general y el chileno en particular deberían ofrecer una robusta protección del derecho que tiene toda persona a mantener reserva y control sobre su información genética.

El derecho internacional ofrece importantes propuestas normativas para una más efectiva tutela del derecho a la intimidad genética, aunque únicamente en la línea de declaraciones. La Unión Europea, por su parte, cuenta con instrumentos jurídicos recientes para regular la protección del mencionado derecho en el espacio comunitario, los que por cierto son vinculantes para los Estados de la unión.

Atender a estos estándares por parte de un ordenamiento jurídico como el chileno resulta esencial por al menos dos razones. En primer lugar, porque en conjunto estos ordenamientos contienen las más modernas normas y mecanismos del mundo en materia de intimidad genética. En segundo lugar, porque la

1 Casado (2014), p. 14.

2 PierCe (2006), p. G-19.

3 McPherson (2006), p. 124.

4 Artículo $4^{\circ}$, letra a), número iv), de la Declaración Internacional sobre los Datos Genéticos Humanos.

5 Álvarez (2017), p. 57. 
efectiva tutela del mencionado derecho fundamental constituye una garantía para el efectivo disfrute de la libertad y la igualdad de los seres humanos, frente a las amenazas que pueden derivar del mal uso de aquella información.

A partir de los antecedentes recién expuestos surgen, sin duda, diversas preguntas. La que desea responder esta investigación puede ser formulada de la siguiente manera: ¿es adecuada la protección otorgada al derecho fundamental a la intimidad genética por el ordenamiento jurídico chileno, en relación con el estándar establecido por el derecho internacional y por el derecho comunitario?

Para este efecto conviene precisar a qué se alude con las expresiones "derecho internacional" y "derecho comunitario", incluidas en la pregunta y sobre las cuales se construye el estándar de evaluación. Con la primera se hace referencia a las declaraciones emanadas de Naciones Unidas y que forman parte del derecho internacional general. Con la segunda de ellas se alude a las normas dictadas por la Unión Europea y que resultan obligatorias para los Estados que la integran.

Como se sabe, ninguno de los elementos recién mencionados constituyen derecho de obligatorio cumplimiento para el Estado de Chile. Sin embargo, tal situación no genera problema alguno para la investigación que se ofrece. Esto se debe a que no se pretende elucidar cuáles son las normas del derecho internacional a las que se encuentra sometido nuestro país en relación con el derecho a la intimidad genética. Lo que se desea evidenciar es la distancia que existe entre el estándar establecido por normas y declaraciones supranacionales, por una parte, y la regulación ofrecida por el ordenamiento jurídico chileno, por otra.

Formuladas estas precisiones, resulta posible explicitar la hipótesis de este trabajo: que el ordenamiento jurídico chileno carece de una adecuada protección del derecho fundamental a la intimidad genética en relación con el estándar establecido por los derechos internacional y comunitario, porque carece de una regulación expresamente dirigida a tutelar ese derecho y porque las normas actualmente vigentes que pueden vincularse con este objetivo son insuficientes para satisfacer el mencionado estándar.

Con la finalidad de responder la pregunta que guía la investigación, el discurso que sigue se vertebra en torno a cuatro apartados. El primero de ellos explica concisamente el significado y la jerarquía iusfundamental de la intimidad genética. El apartado II presenta el estándar establecido por el derecho internacional y por el derecho comunitario para la adecuada protección del derecho fundamental a la intimidad genética. El apartado III expone la regulación ofrecida por el derecho chileno que puede resultar pertinente para la tutela de aquel derecho fundamental. 
El último apartado ofrece las conclusiones, mediante el contraste entre lo expuesto en los dos apartados anteriores.

\section{OBJETO, SIGNIFICADO Y JERARQUÍA IUSFUNDAMENTAL DEL DERECHO A LA INTIMIDAD GENÉTICA}

El objetivo del presente apartado es precisar el significado del derecho a la intimidad genética y mostrar que en el ordenamiento jurídico chileno tiene jerarquía iusfundamental. Con tal finalidad, el apartado se inicia explicitando el objeto tutelado por este derecho.

\section{ObJETO PROTEGIDO POR EL DERECHO A LA INTIMIDAD GENÉTICA}

Para explicar el significado del derecho a la intimidad genética es necesario precisar en primer lugar el objeto protegido por el mismo. Al efecto, conviene recordar alguna información tan básica como esencial en relación con la genética.

Las células que componen el cuerpo humano cuentan con un núcleo, en cuyo interior hay 23 pares de cromosomas. En términos sencillos, cada cromosoma está constituido por ácido desoxirribonucleico (en adelante $\mathrm{ADN}$ ) y proteínas unidas a aquel, los que se han aglomerado, de modo que un cromosoma es ADN más proteína ${ }^{6}$. El ADN, por su parte, está constituido por genes o, para decirlo de manera más precisa, cada uno de los fragmentos que constituyen el ADN se denomina gen ${ }^{7}$. Los genes, por su parte, son los "elementos que contienen la información que determina las características de las especies como conjunto, así como de cada uno de sus individuos"8. De este modo, el ADN es el "portador de la información genética"'. Los seres vivos poseen información genética distintiva en el mundo natural; esto imposibilita la invasión de otras formas de vida. Y,

\footnotetext{
6 Como explican KLUG et al. (2006), p. 336, “en las células eucarióticas convencionales (...) el DNA y las proteínas se acomplejan en una estructura nucleoproteica denominada cromosoma”.

7 En términos científicos, "un gen se define de una forma general como un fragmento de la secuencia del DNA que corresponde a una sola proteína o a una colección de variantes de una proteína (o a una molécula de RNA catalítico o estructural, en el caso de los genes que no producen proteína sino RNA)", según explican AlberTs et al. (2010), p. 7.

8 Alberts et al. (2010), p. 195.

9 Alberts et al. (2010), pp. 195 y 196.
} 
dentro de cada especie, los individuos poseen una información genética única y diferenciada del resto ${ }^{10}$.

Pues bien, el objeto protegido por el derecho a la intimidad genética es precisamente la información genética. Corresponde, por tanto, explicar el significado de esta expresión. La expresión información genética "se vincula por un lado con el tema de la evolución de los seres vivos y por el otro con el concepto general de información"11. En efecto, y en relación con esas dos perspectivas, la información genética consiste en datos que generan condicionantes respecto del individuo, respecto de los descendientes del mismo y respecto de la especie a la que el individuo pertenece ${ }^{12}$. Así, en "un primer nivel, la 'identidad genética', se corresponde con la constitución genética de la persona individual; un segundo nivel con la capacidad de inferir la expresión genotípica de una persona a partir de su familia, como condición hereditaria normalmente de carácter recesivo, y un tercer nivel, destinado a reconocer una esfera social a la genética humana"13. A continuación se explican más detalladamente estas ideas.

Con relación a los seres humanos, la información genética provee antecedentes que permiten (a) que la persona pueda ser identificada; (b) que la persona pueda ser relacionada con otros sujetos, vivos o muertos; (c) conocer el estado de salud actual de un sujeto; (d) prever la mayor o menor propensión a padecer patologías futuras; (e) conseguir datos relevantes que pueden trascender el ámbito exclusivamente individual para afectar a la descendencia, y (f) aportar información para el futuro, aunque la relevancia de dicha información no se conozca en el momento de extraer las muestras biológicas ${ }^{14}$.

De esta manera, la información genética aporta datos propios de la privacidad del sujeto con dos características que son, además, especialmente sensibles. De un lado, se trata de información que permanece inmutable, debido a que "no depende de factores medioambientales o del paso del tiempo sino que permanece estable a lo largo de toda nuestra vida, e incluso una vez que hayamos muerto"15.

\footnotetext{
10 Bergel (2018), p. 90.

11 Solari (2004), p. 86.

12 En palabras de MiÑo (2016), p. 10, la información genética "contiene y transmite la herencia, encierra en sí los datos básicos de la configuración de nuestra biología individual y, por consiguiente, de la configuración genética de nuestro grupo biológico".

13 Corcoy (2014), p. 93.

14 Gómez (2008), p. 61.

15 Miño (2016), p. 10.
} 
De otro lado, se trata de datos que persistirán durante generaciones, que pueden carecer de importancia en la actualidad, pero no así en el futuro ${ }^{16}$.

\section{SignifiCADO Y CONTENIDO DEL DERECHO A LA INTIMIDAD GENÉTICA}

Para precisar el significado y contenido del derecho fundamental a la intimidad genética es necesario considerar diversas variables. De un lado, que el conocimiento de los datos genéticos presenta la entidad suficiente para causar perjuicios considerables al individuo, lo que torna necesaria una protección privilegiada ${ }^{17}$. De otro lado, y al mismo tiempo, se debe tener como precaución no asumir definiciones demasiado estrictas, o por el contrario, demasiado amplias, buscando el equilibrio entre los intereses legítimos de los ciudadanos y actividades sociales como la investigación científica ${ }^{18}$. Por último, y no por ello menos importante, debe ser reconocida la dificultad de protección de los datos genéticos, con base en que las posibilidades de acceso a este tipo de información resultan ilimitadas ${ }^{19}$.

Desde tales coordenadas, el derecho a la intimidad genética puede ser definido como aquel derecho que tiene por finalidad tutelar la información genética de una persona, es decir, aquellos datos que se encuentran en sus genes y que determinan las características del sujeto, de sus descendientes y de la especie a la que pertenece ${ }^{20}$.

La noción de intimidad genética trasciende el concepto clásico de intimidad, pues no es un simple derecho de defensa, sino más bien un derecho que otorga diversas facultades que requieren del titular una actitud activa ${ }^{21}$. De ahí que sea

16 Brena Sesma (2008), p. 117.

17 Bergel (2018), p. 107. Misma idea fue presentada en el artículo "La libertad del hombre y el genoma", de Peces Barba (1993), pp. 317-335, donde se establece la necesidad de tutelar el respeto de la intimidad y confidencialidad de los datos genéticos, la existencia de un derecho de acceso a los datos genéticos de cada individuo, si este lo solicita, y si dichos datos se encuentren en un registro o en una base de datos autorizados, e inclusive la necesidad de crear y designar organismos públicos de tutela y vigilancia.

18 SuÁrez Espino (2008), p. 88.

19 Bergel (2018), p. 89.

20 En similar sentido, VelásQuez (2008), p. 447, expresa que el derecho a la intimidad genética "es aquel que protege la información derivada del genoma”.

21 SuÁrez Espino (2008), p. 89. Ya anteriormente a nivel nacional, Figueroa Yáñez (2003), p. 69, había advertido que "Los descubrimientos genéticos de nueva data han hecho necesario ampliar una vez más el ámbito de estos derechos (derecho a la intimidad y confidencialidad). En efecto, además de otros ámbitos que ya estaban protegidos, debe agregarse ahora todo el ámbito de la intimidad y confidencialidad genéticas”. 
posible sostener que, para que la información genética sea efectivamente resguardada, es necesario que el titular del derecho fundamental cuente con determinadas atribuciones tendientes a asegurar la protección de su derecho fundamental. Estas atribuciones expresan el contenido mínimo del derecho e incluyen a lo menos:

a) Derecho a reserva: La facultad de impedir la intromisión de terceros en la información genética del titular del derecho fundamental, lo que significa evitar intromisiones en "el genoma humano en última instancia y, por derivación, [en] cualquier tejido o parte del cuerpo humano en el que se encuentre esa información genética" 22 .

b) Derecho a control: La libertad para "determinar quién y en qué condiciones puede acceder a la información de su genoma" 23 . De esa forma, "tal conocimiento o el tratamiento de la información genética sólo serán lícitos cuando se hagan con el consentimiento del sujeto"24.

c) Derecho a tutela: La posibilidad "de exigir la intervención de los poderes públicos para proporcionar una efectiva protección a la información genética”25, siendo posible requerir del Estado "la articulación de procedimientos y órganos de control para garantizar y proteger este derecho" 26 .

\section{JERARQUÍA IUSFUNDAMENTAL DEL DERECHO A LA INTIMIDAD GENÉTICA}

Ni la Declaración Universal de Derechos Humanos, ni el Pacto Internacional de Derechos Civiles y Políticos, ni la Convención Americana sobre Derechos Humanos expresan de manera directa el derecho a la intimidad genética. Tampoco la Constitución chilena. Esta omisión en los textos no permite, sin embargo, sostener la inexistencia del derecho fundamental a la intimidad genética. Esto se debe a que los derechos fundamentales no son solo aquellos expresados en normas iusfundamentales directamente estatuidas en la Constitución o en los tratados. También tienen esa calidad aquellos que derivan de la interpretación de dichas normas ${ }^{27}$.

22 Ruiz Miguel (2001), p. 151.

23 Ruiz Miguel (2001), p. 151.

24 Álvarez (2017), p. 57.

25 Ruiz Miguel (2001), p. 152.

26 Caruso (2012), p. 141.

27 La doctrina admite la existencia de derechos fundamentales que no se encuentran directamente expresados en los textos iusfundamentales. En este sentido, por ejemplo, AlEXY (2001), pp. 63-66, que habla de derechos 
El derecho fundamental a la intimidad genética es uno de esos derechos que derivan de la interpretación de las normas iusfundamentales directamente estatuidas en la Constitución y en los instrumentos internacionales. En particular, deriva de lo que los textos normativos usualmente denominan derecho a la vida privada ${ }^{28}, y$ que parte de la doctrina llama derecho a la intimidad o a la privacidad ${ }^{29}$. Por ello resulta imprescindible explicitar el modo en que ambos derechos se vinculan o, más precisamente, en qué sentido se puede sostener que el primero deriva del segundo.

La doctrina chilena tradicional ha vinculado el derecho a la vida privada con la vida doméstica, en particular con las relaciones interpersonales que se generan en el entorno familiar ${ }^{30}$. Una perspectiva más actual y por cierto al mismo tiempo más amplia permite distinguir diversas dimensiones dentro del concepto de vida privada (o privacidad) ${ }^{31}$. Estas diversas dimensiones derivan del carácter evolutivo que presenta este derecho fundamental, que debe ir adaptándose a los cambios culturales valóricos y tecnológicos que afectan al ser humano ${ }^{32}$. Entre esas dimensiones actualmente reconocidas se encuentran el derecho a no ser perturbado, el derecho a dignidad individual y el derecho a controlar la información personal 33 .

otorgados por normas iusfundamentales adscritas, y NoGUEIRA (2007), pp. 253-254, que utiliza la expresión "derechos fundamentales implícitos". El Tribunal Constitucional chileno también ha admitido la existencia de estos derechos fundamentales; por ejemplo, en la sentencia recaída en la causa rol No 2454-2013 INA, de 13 de mayo de 2014 , especialmente considerandos $15^{\circ}$ a $17^{\circ}$.

28 Artículo 12 de la Declaración Universal, artículo 17.1 del Pacto Internacional de Derechos Civiles y Políticos, artículo 11.2 de la Convención Americana sobre Derechos Humanos y artículo 19, número 4, de la Constitución chilena.

29 Dejamos de lado por ahora la discusión respecto de las diferencias entre los significados de "vida privada", "intimidad" y "privacidad", sobre los cuales no parece existir coincidencia entre los autores. Con todo, al parecer, la mayoría, como ARellano y OchOA (2013), p. 194; Ríos (2003), p. 3, y MALEm (1993), pp. 170171 , sostiene que la intimidad tendría un significado más estrecho que la vida privada, posición con la que por cierto coincidimos. FigUerOA (2013), p. 860, por su parte, parece hacer sinónimas las expresiones "vida privada" y "privacidad", idea con la que también coincidimos.

30 Silva (1997), p. 188; Molina (2006), p. 219, y Evans (1999), p. 213. Este último autor, en sintonía con los demás mencionados, alude al ámbito en el que la persona y sus cercanos establecen sus relaciones interpersonales.

$31 \mathrm{Al}$ respecto, ver FigUeROA (2013), quien propone una sistematización de las categorías de privacidad y de clasificación de la jurisprudencia chilena recaída en recursos de protección.

32 Como acertadamente sostiene Herrera (2016), p. 88, el derecho fundamental a la vida privada "es considerado un derecho de difícil definición y delimitación debido al carácter relativo que le caracteriza, pues es una noción que muta con el transcurso del tiempo y es distinta en cada sociedad y cultura”.

33 Bronfman et al. (2012), pp. 129 y 130. 
En todo caso, en lo más esencial del derecho fundamental a la vida privada se encuentra el "derecho a ser dejado en paz". Se puede sostener, de manera general, que el derecho a la vida privada consiste en la facultad que se otorga a una persona para determinar quiénes tendrán acceso a determinados aspectos de su vida privada, esto es, a aquellos aspectos de su vida que no desea que sean de conocimiento público o general.

En dicho contexto, el derecho a la intimidad genética puede ser adscrito sin dificultad al derecho fundamental a la vida privada no solo porque así ha sido sostenido ${ }^{34}$, sino en especial si se consideran dos elementos esenciales de este último. En primer lugar, un elemento de contenido: se trata de un derecho que otorga "una protección general, abierta al desarrollo del concepto de vida privada" 35 . En segundo lugar, un elemento de contexto: se trata de un derecho que "se formula como reacción al perfeccionamiento de las tecnologías de la información"36, superando las concepciones ilustradas que limitaban la privacidad al hogar y a la correspondencia. De esta manera, el derecho a la intimidad genética no es más ni menos que una precisión del derecho fundamental a la vida privada, aplicado al ámbito de la información genética.

Si el derecho a la intimidad genética constituye una precisión del derecho fundamental a la vida privada, como una especificación del mismo en el ámbito de la información genética, aquel derecho también tiene carácter iusfundamental. En otras palabras, goza de la jerarquía de los demás derechos fundamentales y genera los efectos de este subordenamiento jurídico ${ }^{37}$. Esto, como es obvio, significa que es deber del Estado respetarlo, protegerlo y promoverlo ${ }^{38}$. Por tanto, debe realizar las adecuaciones jurídicas e institucionales necesarias para su efectivo disfrute, evitando vulnerarlo, tutelándolo frente a terceros y removiendo los obstáculos que lo afecten. El Estado, por tanto, tiene deberes de acción y deberes de omisión frente a este derecho fundamental, como frente a la generalidad de los derechos que pertenecen a dicha categoría.

\footnotetext{
34 Velásquez (2008), p. 451.

35 Bronfman et al. (2012), p. 128.

36 SÁNCHEZ (2002), p. 257.

37 En este mismo sentido, aunque únicamente en el ámbito constitucional, AleXY (2001), p. 70.

$38 \mathrm{El}$ artículo 50, inciso segundo, de la Constitución chilena en lo pertinente prescribe: "Es deber de los órganos del Estado respetar y promover tales derechos, garantizados por esta Constitución, así como por los tratados internacionales ratificados por Chile y que se encuentren vigentes".
} 
En concreto, y a partir del significado y contenido de este derecho fundamental, el Estado chileno está obligado a establecer normas y mecanismos que permitan (a) impedir la intromisión de terceros en la información genética del titular del derecho; (b) asegurar que la persona podrá controlar quién y en qué condiciones puede acceder a su información genética, y (c) que el propio Estado pueda intervenir para proteger este derecho, incluyendo la creación de procedimientos y órganos destinados a dicha finalidad. Como se verá a continuación, los derechos internacional y comunitario tienden a asegurar precisamente el cumplimiento de estas obligaciones.

\section{ESTÁNDAR DE PROTECCIÓN DEL DERECHO FUNDAMENTAL}

\section{A LA INTIMIDAD GENÉTICA}

El objetivo del presente apartado es presentar el estándar establecido por el derecho internacional y por el derecho comunitario para la adecuada protección del derecho fundamental a la intimidad genética. Para este efecto, y en primer lugar, se mencionarán los textos jurídicos que concurren a la conformación de dicho estándar. Y, en segundo lugar, se sistematizarán los principios y mecanismos establecidos por esos mismos instrumentos.

\section{INSTRUMENTOS DE REFERENCIA}

Según se anunció en la introducción de este trabajo, dos son los órdenes normativos que sirven de referencia para construir el estándar con el que se contrastará el derecho chileno.

El primero de ellos es el derecho internacional, expresado en las declaraciones emanadas de Naciones Unidas y que forman parte del derecho internacional general. Tres son los instrumentos incluidos en esta categoría: la Declaración Universal del Genoma Humano y los Derechos Humanos (1997), el instrumento más importante dentro del Sistema de Naciones Unidas sobre la materia ${ }^{39}$; la Declaración Internacional sobre Datos Genéticos Humanos (2003), y la Declaración de Bioética y Derechos Humanos (2005). Todos estos instrumentos han sido proclamados en el marco de la Organización de las Naciones Unidas para la Educación, la Ciencia y la Cultura (Unesco) y constituyen derecho declaratorio o soft law ${ }^{40}$.

39 Velásquez (2008), p. 449.

40 GÓmez (2010), p. 161. 
El segundo de esos órdenes normativos es el derecho comunitario, esto es, el vigente en la Unión Europea. En este caso, son dos los instrumentos de relevancia: la Carta de los Derechos Fundamentales de la Unión Europea (2000), proclamada por el Parlamento Europeo, el Consejo de la Unión Europea y por la Comisión Europea, y el Reglamento 2016/679, del Parlamento Europeo, cuya vigencia inició el 25 de mayo de 2018.

Aunque, evidentemente, estas regulaciones no son en modo alguno imperativas para Chile, constituyen un ineludible referente por al menos dos razones. En primer lugar, porque ofrecen la regulación más robusta del mundo en materia de protección de datos personales ${ }^{41}$. Y en segundo lugar porque "la mayoría de las leyes en Latinoamérica se han dictado siguiendo las normas de la Unión Europea a efectos de ser considerados países con una legislación adecuada” ${ }^{2}$.

\section{PRINCIPIOS Y MECANISMOS QUE CONSTITUYEN EL ESTÁNDAR DE REFERENCIA}

Los instrumentos internacionales recién mencionados establecen un conjunto de principios y de mecanismos para asegurar el efectivo disfrute del derecho fundamental a la intimidad genética. A continuación se expondrá cada uno de ellos.

\subsection{Principio de autonomía}

El derecho fundamental a la intimidad genética es un derecho de libertad ${ }^{43}$. De ahí que no resulte extraño que el principio de autonomía sea uno de los fundantes de la regulación internacional del mismo. Dicho principio está expresamente reconocido en la Declaración de Bioética y Derechos Humanos, la que al respecto establece: "Se habrá de respetar la autonomía de la persona en lo que se refiere a la facultad de adoptar decisiones" 44 .

Este principio reconoce el derecho que tiene cada individuo de tener su propio punto de vista, elegir y realizar acciones conforme a los valores y creencias per-

\footnotetext{
41 BeCERra (2013), p. 165.

42 Proyecto de ley, Boletín 11.092-07, p. 3.

43 El principio general de libertad puede ser definido, siguiendo a ALEXY (2001), p. 333, como aquel que establece dos cosas: "Por una parte, a cada cual le está permitido prima facie -es decir, en caso de que no intervengan restricciones- hacer y omitir lo que quiera (norma permisiva). Por otra, cada cual tiene prima facie, es decir, en la medida que no intervengan restricciones, un derecho frente al Estado a que éste no impida sus acciones y omisiones, es decir, no intervenga en ellas (norma de derechos)".
}

44 Artículo 5o de la Declaración de Bioética y Derechos Humanos. 
sonales, a la responsabilidad individual ${ }^{45}$. De esa forma se reconoce al individuo una esfera de autodeterminación en lo relativo al análisis, conocimiento y uso de su información genética: él decide cuándo, a quién y en qué medida permite el acceso a su información genética ${ }^{46}$.

\subsection{Consentimiento}

a) Necesidad de consentimiento. La Declaración Internacional sobre los Datos Genéticos Humanos define al consentimiento como el "permiso específico, informado y expreso que una persona da libremente para que sus datos genéticos sean recolectados, tratados, utilizados y conservados" $\$ 7$.

b) Requisitos del consentimiento. En el ámbito internacional, la Declaración Universal del Genoma Humano y los Derechos Humanos estableció que el consentimiento debe ser previo, libre e informado ${ }^{48}$. Estas exigencias fueron complementadas por la Declaración Internacional sobre Datos Genéticos Humanos, al disponer que el consentimiento debe ser específico y expreso ${ }^{49}$. A partir de estas regulaciones, algunos autores desprenden como requisito implícito que el consentimiento conste en documento escrito ${ }^{50}$.

En el ámbito europeo, la Carta de los Derechos Fundamentales de la Unión Europea reconoce que en el marco de la medicina y la biología se debe respetar el consentimiento libre e informado de la persona ${ }^{51}$. Este instrumento precisa que la protección de datos de carácter personal exige un tratamiento de forma leal, para fines concretos, y sobre la base del consentimiento de la persona afectada ${ }^{52}$. El reciente Reglamento 2016/679, de la Unión Europea, establece que la carga de la prueba del consentimiento recae en el responsable del tratamiento de datos genéticos. Exige que, en caso de darse en el contexto de una declaración escrita que se refiera a otros asuntos, el consentimiento deba ser solicitado mediante una

45 GÓmez (2010), p. 149.

46 Brena Sesma (2008), p. 116.

47 Artículo $2^{\circ}$, número iii), de la Declaración Internacional sobre Datos Genéticos Humanos.

48 Artículo 5º letra b), de la Declaración Universal del Genoma Humano y los Derechos Humanos.

49 Artículo $6^{\circ}$ de la Declaración Internacional sobre Datos Genéticos Humanos.

50 Ruiz Miguel (2001), pp. 156-157.

51 Artículo $3^{\circ}$ de la Carta de los Derechos Fundamentales de la Unión Europea.

52 Artículo $8^{\circ}$ de la Carta de los Derechos Fundamentales de la Unión Europea. 
presentación donde se distinga claramente de los demás, de forma inteligible, de fácil acceso, y con un lenguaje claro y sencillo ${ }^{53}$.

c) Revocación del consentimiento. En cuanto a la revocación del consentimiento, la Declaración de Bioética y Derechos Humanos establece que el interesado debe ser adecuadamente informado acerca de dicha posibilidad, sin que exista perjuicio o sanción económica en su contra ${ }^{54}$.

d) Excepciones al consentimiento. Si una persona no está en condiciones de otorgar su consentimiento, la regulación internacional dispone que solo se podrá efectuar una investigación sobre su genoma si representa un beneficio directo y previsible para su salud. Si no existe dicho beneficio, excepcionalmente se podrá realizar aquella investigación con la mayor prudencia y procurando no exponer al interesado sino a un riesgo y una coerción mínimos ${ }^{55}$.

\subsection{Asesor genético}

La Declaración Internacional sobre los Datos Genéticos Humanos define la asesoría genética como un "procedimiento destinado a explicar las posibles consecuencias de los resultados de una prueba o un cribado genéticos y sus ventajas y riesgos y, en su caso, para ayudar a una persona a asumir esas consecuencias a largo plazo. Tiene lugar tanto antes como después de una prueba o un cribado genéticos" 56 .

El objetivo del asesor genético es otorgar asesoramiento y apoyo psicoemocional para promover decisiones informadas en el titular del derecho a la intimidad genética, para que pueda adaptarse de la mejor manera al riesgo o condición genética ${ }^{57}$. De ahí que, de acuerdo con lo dispuesto en la Declaración Internacional sobre los Datos Genéticos Humanos, dicha asesoría constituye un imperativo ético cuando se trata de pruebas genéticas que puedan tener consecuencias importantes para la salud de una persona ${ }^{58}$.

53 Artículos 7.1 y 7.2 del Reglamento 2016/679, de 27 de abril de 2016, de la Unión Europea.

54 Artículo 6o de la Declaración Internacional sobre Datos Genéticos Humanos.

55 Artículo 5으. letras b) y c), de la Declaración Universal del Genoma Humano y los Derechos Humanos.

56 Artículo $2^{\circ}$, número xiv, de la Declaración Internacional sobre los Datos Genéticos Humanos.

57 Margarit (2017), p. 525.

58 Artículo 11 de la Declaración Internacional sobre los Datos Genéticos Humanos. 


\subsection{Principio de confidencialidad}

Según se ha expresado, el derecho fundamental a la intimidad genética constituye una especificación del derecho fundamental a la vida privada, aplicado al ámbito de la información genética. En efecto, la información genética forma parte de aquellos aspectos de la vida de una persona que no deben ser de conocimiento público o general, de modo que ostenta "un carácter confidencial y privado" 59. En perfecta coherencia con ello, los instrumentos internacionales y comunitarios consagran de manera destacada el principio de confidencialidad.

a) La exigencia de confidencialidad. En el ámbito internacional, la Declaración Universal del Genoma Humano y los Derechos Humanos exige proteger la confidencialidad de los datos genéticos asociados con una persona identificable ${ }^{60}$. Agrega que es obligación de la institución o persona que efectúa la investigación la confidencialidad de los datos genéticos ${ }^{61}$. La Declaración Internacional sobre Datos Genéticos Humanos precisa que el Estado debe adoptar las medidas que protejan la privacidad de las personas y la confidencialidad de los datos humanos asociados a una persona, a una familia o a un grupo identificable ${ }^{62}$.

En similar sentido, aunque de manera más bien general, se pronuncian las normas europeas. En efecto, la Carta de los Derechos Fundamentales de la Unión Europea se limita a disponer que toda persona tiene derecho a la protección de los datos de carácter personal que le conciernen ${ }^{63}$.

b) Consecuencias del principio de confidencialidad. Las consecuencias del principio de confidencialidad son a lo menos las siguientes:

1) La información genética no debe ser revelada a terceros sin autorización expresa $^{64}$.

2) La información genética no puede ser utilizada ni revelada para fines distintos de los que determinaron su acopio o para los que se obtuvo el consentimiento ${ }^{65}$. Sin embargo, la normativa europea precisa que "el tratamiento ulterior de los

59 Gómez (2010), p. 152.

60 Artículo 7o de la Declaración Universal del Genoma Humano y los Derechos Humanos.

61 Artículo 7o de la Declaración Universal del Genoma Humano y los Derechos Humanos.

62 Artículo 14, letra a), de la Declaración Internacional sobre Datos Genéticos Humanos.

63 Artículo 8.1 de la Carta de los Derechos Fundamentales de la Unión Europea.

64 Gómez (2010), p. 152.

65 Artículo 90 de la Declaración Universal sobre Bioética y Derechos Humanos, y artículo 5.1, letra b), del Reglamento 2016/679, de 27 de abril de 2016, de la Unión Europea. 
datos personales con fines de archivo en interés público, fines de investigación científica e histórica o fines estadísticos no se considerará incompatible con los fines iniciales" 66 .

3) Los datos genéticos no deben permanecer asociados a una persona determinada, a menos que hubieren sido obtenidos con fines de investigación y aquella asociación sea necesaria para los fines de la misma ${ }^{67}$. En cualquier caso, los datos genéticos no deben permanecer asociados a una persona determinada por más tiempo del necesario para cumplir los fines con que fueron recolectados o ulteriormente tratados ${ }^{68}$.

4) El Estado debe adoptar medidas adecuadas para asegurar el efectivo respeto del contenido de este derecho fundamental ${ }^{69}$.

c) Excepciones al principio de confidencialidad. El principio de confidencialidad reconoce ciertas excepciones en los instrumentos en análisis. Entre ellas es posible mencionar las siguientes ${ }^{70}$ :

1) Consentimiento del titular del derecho fundamental a la intimidad genética, el que debe ser previo, libre, expreso, específico e informado, y de conformidad con lo establecido por el derecho interno y por el derecho internacional de los derechos humanos ${ }^{71}$.

2) Obtención de datos genéticos con fines de medicina forense o como parte de procedimientos civiles o penales u otras actuaciones legales, incluidas las pruebas de determinación de parentesco, los que deben ser obtenidos de conformidad con la ley y con el derecho internacional de los derechos humanos ${ }^{72}$. La doctrina

66 Artículo 5.1, letra b), del Reglamento 2016/679, de 27 de abril de 2016, de la Unión Europea.

67 Artículo 14, letra d), de la Declaración Internacional sobre Datos Genéticos Humanos.

68 Artículo 14, letra e), de la Declaración Internacional sobre Datos Genéticos Humanos, y artículo 5.1, letra e), del Reglamento 2016/679, de 27 de abril de 2016, de la Unión Europea.

69 Artículo 22 de la Declaración Universal sobre Bioética y Derechos Humanos y artículo 51.1 de la Carta de Derechos Fundamentales de la Unión Europea. Esta última disposición establece, de manera algo genérica, que los Estados miembros respetarán los derechos y observarán los principios de dicha carta, y promoverán su aplicación.

70 El derecho de la Unión Europea incluye casos adicionales a los señalados en este listado. Por la extensión del presente trabajo no resulta posible referirse a todos ellos. Por tanto, a continuación solo se indican aquellas excepciones en las que coinciden las declaraciones internacionales y el derecho de la Unión Europea.

71 Artículo 14, letra b), y artículo 2º, número iii), de la Declaración Internacional sobre Datos Genéticos Humanos, y artículo 9.2, letra a), del Reglamento 2016/679, de 27 de abril de 2016, de la Unión Europea.

72 Artículo 12 de la Declaración Internacional sobre Datos Genéticos Humanos, y artículo 9.2, letra f), del Reglamento 2016/679, de 27 de abril de 2016, de la Unión Europea. 
entiende que esta excepción al principio de confidencialidad se refiere exclusivamente a la investigación, el descubrimiento y el enjuiciamiento de delitos penales o de pruebas de determinación de parentesco ${ }^{73}$.

3) Razones imperiosas para excluir la confidencialidad, motivos importantes de interés público o un interés público esencial, así establecidos de manera restrictiva por el ordenamiento jurídico correspondiente ${ }^{74}$.

\subsection{Principio de no discriminación}

El principio de no discriminación constituye un principio de ius $\operatorname{cogens}^{75}$, de modo que se encuentra en la cima del ordenamiento jurídico internacional ${ }^{76}$. La información genética entregada por los genes de un individuo, por su parte, puede originar prácticas discriminatorias en contra del mismo o de sus descendientes. De ahí que no resulte extraño que el principio de no discriminación se aplique de manera específica en el ámbito del derecho a la intimidad genética.

En este sentido, la Declaración Universal del Genoma Humano y los Derechos Humanos prescribe: "Nadie podrá ser objeto de discriminaciones fundadas en sus características genéticas"77. Complementando esta orientación, la Declaración Internacional sobre los Datos Genéticos Humanos dispone que se debería hacer todo lo posible para que los datos genéticos no sean utilizados con fines discriminatorios, o de manera que provoquen la estigmatización de una persona, una familia, un grupo o comunidades $^{78}$. En el mismo sentido, pero de manera más categórica, la Declaración Universal sobre Bioética y Derechos Humanos establece que nadie debería ser sometido a discriminación o estigmatización alguna ${ }^{79}$.

\footnotetext{
73 Velásquez (2008), p. 451, y Brena Sesma (2008), p. 121.

${ }^{74}$ Las transcritas son las diversas fórmulas semánticas utilizadas por los instrumentos de referencia: artículo $9^{\circ}$ de la Declaración Universal del Genoma Humano y los Derechos Humanos; artículo 14, letra b), de la Declaración Internacional sobre Datos Genéticos Humanos, y artículo 9.2, letra g), del Reglamento 2016/679, de 27 de abril de 2016, de la Unión Europea.

$75 \mathrm{Al}$ respecto, la Corte Interamericana de Derechos Humanos ha sostenido en la Opinión Consultiva No 18 , de 17 de septiembre de 2003, párrafo 101, que los principios de igualdad y de no discriminación "pertenece[n] al ius cogens, puesto que sobre él [ellos] descansa todo el andamiaje jurídico del orden público nacional e internacional y es un principio fundamental que permea todo el ordenamiento jurídico".

76 QuisPe (2010), p. 45.

77 Artículo 6o de la Declaración Universal del Genoma Humano y los Derechos Humanos.

78 Artículo 7o, letra a), de la Declaración Internacional sobre los Datos Genéticos Humanos.

79 Artículo 11 de la Declaración Universal sobre Bioética y Derechos Humanos.
} 
En el ámbito europeo, la Carta de los Derechos Fundamentales de la Unión Europea vincula de forma expresa el derecho a la intimidad genética y el principio de no discriminación. Al respecto dispone que se prohíbe toda discriminación y en particular la ejercida por razón de características genéticas ${ }^{80}$.

\subsection{Agencia de control}

Existe "cierto consenso a nivel comparado sobre la necesidad de contar con una institución que vele por el adecuado resguardo del Derecho a la Protección de los Datos Personales"81. Esta necesidad es, por cierto, igualmente aplicable en el ámbito de la información genética ${ }^{82}$. Es por ello que en la actualidad varios países ya cuentan con una autoridad de control, entre ellos Alemania, Francia, Australia, Reino Unido, España y México ${ }^{83}$.

En coherencia con aquel consenso, la Declaración Internacional sobre los Datos Genéticos Humanos señala que los Estados pueden disponer dispositivos de supervisión, gestión y conservación de la información genética. Sugiere que el establecimiento de esta clase de dispositivos se someta a los principios de independencia, multidisciplinariedad, pluralismo y transparencia ${ }^{84}$.

La Carta de los Derechos Fundamentales de la Unión Europea establece, de manera general, que corresponderá a una autoridad independiente controlar el respeto de las normas relativas a la protección de datos personales. Precisando aquella norma, el Reglamento de la Unión Europea dispone que cada Estado miembro deberá establecer una o más autoridades públicas independientes para proteger los derechos y las libertades fundamentales de las personas físicas en lo que respecta a los datos personales ${ }^{85}$, incluido por cierto los del ámbito genético ${ }^{86}$.

80 Artículo 21 de la Carta de los Derechos Fundamentales de la Unión Europea.

81 Consejo para la Transparencia (2015), p. 6.

82 Ruiz Miguel (2001), pp. 152-153.

83 Consejo para la Transparencia (2015), p. 6.

84 Artículo 20 de la Declaración Internacional sobre los Datos Genéticos Humanos.

85 Artículo 51.1 del Reglamento 2016/679, de 27 de abril de 2016, de la Unión Europea.

86 Artículo 51.1 del Reglamento 2016/679, de 27 de abril de 2016, de la Unión Europea, en relación con el artículo $4^{\circ}$, número 1 , del mismo texto. 


\subsection{Principio de responsabilidad}

El derecho internacional regula el principio de responsabilidad en el específico ámbito de la vulneración al derecho fundamental a la intimidad genética.

En efecto, y por una parte, la Declaración Universal sobre el Genoma Humano y los Derechos Humanos aplica dicho principio respecto de daños padecidos como consecuencia de una intervención en la información contenida en el ADN de un individuo. $\mathrm{Al}$ respecto dispone que toda persona tiene derecho a "una reparación equitativa de un daño del que pueda haber sido víctima, cuya causa directa y determinante pueda haber sido una intervención en su genoma" 87 .

El Reglamento de la Unión Europea relativo a la protección de las personas físicas en lo que respecta al tratamiento de datos personales, por su parte, consagra expresamente el principio de responsabilidad. Al respecto dispone que la persona que haya sufrido perjuicios materiales o inmateriales como consecuencia de una infracción del mencionado reglamento tendrá derecho a recibir del responsable o el encargado del tratamiento una indemnización por los daños y perjuicios sufridos ${ }^{88}$.

\section{Protección de la intimidad genética en Chile}

De acuerdo con lo anunciado en la introducción del presente trabajo, el objetivo de este apartado III es exponer la regulación ofrecida por el derecho chileno que puede resultar pertinente para la tutela del derecho fundamental a la intimidad genética. En forma previa se mencionarán los textos jurídicos que se han utilizado para presentar la situación nacional.

\section{TeXtos LEgales DE REFERENCIA}

Los textos legales del ordenamiento jurídico chileno que presentan algún contenido relacionado con el derecho fundamental a la intimidad genética son los siguientes: Ley No 19.628 (1999), sobre protección de la vida privada; Ley No 19.970 (2004), crea el Sistema Nacional de Registros de ADN; Ley No 20.120 (2006), sobre la investigación científica en el ser humano, su genoma, y prohíbe

87 Artículo $8^{\circ}$ de la Declaración Universal del Genoma Humano y los Derechos Humanos.

88 Artículo 82.1 del Reglamento 2016/679, de 27 de abril de 2016, de la Unión Europea. 
la clonación humana, y Ley No 20.584 (2012), regula los derechos y deberes que tienen las personas en relación con acciones vinculadas a su atención en salud.

Las cuatro leyes mencionadas, más el reglamento de una de ellas, serán analizadas para presentar el estado en que se encuentra la legislación chilena, en relación con cada uno de los principios y mecanismos establecidos por los derechos internacional y comunitario para la tutela del derecho fundamental a la intimidad genética.

\section{PRINCIPIOS Y MECANISMOS DE TUTELA EN EL DERECHO CHILENO}

A continuación se expondrán las normas incluidas en la legislación chilena que se relacionan con los siete principios y mecanismos establecidos por el derecho internacional y por el derecho comunitario para la más efectiva tutela del derecho fundamental a la intimidad genética. Esta exposición seguirá el mismo orden ofrecido al presentar los principios y mecanismos contenidos en los instrumentos internacionales.

\subsection{Principio de autonomía}

El derecho chileno no contiene norma alguna que de manera expresa reconozca el principio de autonomía de la persona en el ámbito del derecho fundamental a la intimidad genética. Con todo, se debe reconocer que algunas disposiciones son manifestación de aquel, como se verá inmediatamente al analizar el consentimiento.

\subsection{Consentimiento}

a) Necesidad de consentimiento. El ordenamiento jurídico chileno regula expresamente el consentimiento en relación con el derecho a la intimidad genética. $\mathrm{Al}$ efecto prescribe que no pueden ser objeto de tratamiento los datos sensibles ${ }^{89} \mathrm{y}$ que no se podrá investigar ni determinar la identidad genética de un ser humano sin su consentimiento ${ }^{90}$.

\footnotetext{
89 Artículo 10 de la Ley No 19.628 (1999). La ley no incluye la información genética entre los "datos sensibles" mencionados a modo de ejemplo en el artículo $2^{\circ}$, letra g), de la misma ley. No obstante, la genérica referencia a los hechos o aspectos de la vida privada o de la intimidad de la persona en la definición de "datos sensibles" permite incluirla sin dificultad.

90 Artículo 9o de la Ley № 20.120 (2006).
} 
b) Requisitos del consentimiento. La Ley No 20.120 dispone que el consentimiento debe ser escrito ${ }^{91}$, previo, expreso, libre e informado ${ }^{92}$ cuando se trate de investigar o determinar la identidad genética de una persona. La misma ley precisa que, en caso de requerirse para una investigación, existe consentimiento informado cuando la persona que debe prestarlo conoce los aspectos esenciales de aquella, en especial su finalidad, beneficios, riesgos y los procedimientos o tratamientos alternativos. La ley concluye exigiendo que al efecto se le entregue información adecuada, suficiente y comprensible sobre la investigación ${ }^{93}$.

c) Revocación del consentimiento. En toda investigación científica se deberá hacer especial mención del derecho que tiene la persona de revocar su consentimiento en cualquier momento y por cualquier medio, sin que ello importe responsabilidad, sanción o pérdida de beneficio alguno ${ }^{94}$.

d) Excepciones a la exigencia de consentimiento. La legislación chilena incluye las siguientes excepciones al consentimiento otorgado por el titular del derecho:

1) En caso de que el titular del derecho a la intimidad genética no pueda otorgar su consentimiento, dicha voluntad podrá ser suplida por quien corresponda en conformidad con la ley95.

2) La investigación y determinación de la identidad genética de una persona podrá ser autorizada por los tribunales, en los casos y formas establecidos por la ley ${ }^{96}$.

\subsection{Asesor genético}

En Chile no existe norma alguna que establezca la asesoría genética. El ordenamiento tampoco considera la posibilidad de informar, antes o después de una prueba o cribado genético, respecto de posibles consecuencias de los resultados de aquella o este y sus ventajas y riesgos. Este mecanismo no se contempla ni siquiera en el caso de pruebas genéticas que puedan tener consecuencias importantes para la salud de una persona.

\footnotetext{
91 Artículo 11, inciso tercero, de la Ley No 20.120 (2006). El requisito de escrituración se establece en el caso de investigaciones científicas, entre las cuales se puede incluir la investigación genética a que se refiere el artículo $9^{\circ}$ de la misma ley.

92 Artículos 90 y 11, inciso primero, de la Ley No 20.120 (2006).

93 Artículo 11, inciso segundo, de la Ley No 20.120 (2006).

94 Artículo 11, inciso primero, de la Ley No 20.120 (2006).

95 Artículo 9o de la Ley No 20.120 (2006).

96 Artículo 9o de la Ley No 20.120 (2006).
} 


\subsection{Principio de confidencialidad}

a) Exigencia de confidencialidad. La Ley No 20.120 (2006) dispone que la información genética de un ser humano será reservada ${ }^{97}$. Similar disposición se encuentra en la Ley No 19.970, que prescribe que el Sistema Nacional de Registros de $\mathrm{ADN}$ establecido por la misma ley tendrá carácter reservado ${ }^{98}$.

b) Consecuencias del principio de confidencialidad. El ordenamiento jurídico chileno reconoce ciertas consecuencias derivadas del principio de confidencialidad:

1) Los datos del genoma humano que permitan la identificación de una persona deberán ser encriptados para su almacenamiento y transmisión ${ }^{99}$.

2) Se prohíbe solicitar, recibir, indagar, poseer y utilizar información sobre el genoma relativa a una persona ${ }^{100}$.

3) Los datos genéticos deben ser eliminados en los plazos que las diversas leyes establecen. Así, la Ley No 19.970 (2004) señala como regla general la destrucción de los registros genéticos de una persona, una vez concluido el proceso criminal, y que, en cualquier caso, las huellas genéticas de los registros de imputados, víctimas, y de evidencias y antecedentes, deben ser eliminadas transcurridos 30 años desde su incorporación ${ }^{101}$. En el caso del Registro de Condenados, en cambio, no existe disposición que determine el plazo de conservación de la huella genética. Por su parte, la Ley No 20.584 (2012) permite eliminar la ficha clínica una vez transcurridos 15 años desde el último ingreso de información ${ }^{102}$. La Ley No 19.628 (1999) dispone que los datos personales deben ser eliminados por el responsable del banco de datos personales cuando hayan caducado, incluso sin necesidad de requerimiento del titular ${ }^{103}$.

c) Excepciones al principio de confidencialidad. La legislación chilena admite que en ciertos casos se afecte el principio de confidencialidad. Esto ocurre en los siguientes casos:

\footnotetext{
97 Artículo 12 de la Ley No 20.120 (2006).

98 Artículo 2o, inciso primero, de la Ley No 19.970 (2004).

99 Artículo 13 de la Ley No 20.120 (2006).

100 Artículo 14 de la Ley No 20.120 (2006).

101 Artículo 18 de la Ley No 19.970 (2004).

102 Artículo 13 de la Ley No 20.584 (2012).

103 Artículo 6º, incisos primero y tercero, de la Ley No 19.628 (1999).
} 
1) Consentimiento del titular del derecho a la intimidad genética o de quien lo represente ${ }^{104}$.

2) Los tribunales pueden levantar la reserva de la información genética, en los casos y en la forma establecidos por la ley ${ }^{105}$. En el mismo sentido, aunque de manera más específica, la legislación establece que el Ministerio Público Fiscal y los tribunales pueden acceder a la información contenida en el Sistema Nacional de Registros de ADN106.

3) La información personal puede ser tratada cuando sean datos necesarios para la determinación u otorgamiento de beneficios de salud que correspondan a sus titulares ${ }^{107}$.

4) Los organismos públicos pueden tratar los datos personales respecto de las materias de su competencia, sin requerir el consentimiento del titular ${ }^{108}$.

5) La información personal puede ser tratada en los casos que lo autorice la ley ${ }^{109}$.

\subsection{Principio de no discriminación}

Las leyes consultadas incluyen dos normas de interés en relación con el principio de no discriminación aplicado al ámbito de la intimidad genética. Una de ellas se encuentra en la Ley No 20.120 (2006), la que de manera precisa y explícita prohíbe "toda forma de discriminación arbitraria basada en el patrimonio genético de las personas"110. La segunda norma se encuentra en la Ley No 19.970 (2004), que, al regular el Sistema Nacional de Registros de ADN, prohíbe que

104 Artículos 9o y 11 de la Ley No 20.120 (2006), y artículos 11 y 12, inciso primero, del Decreto No 114 , de 22 de noviembre de 2010, del Ministerio de Salud.

105 Artículo 12 de la Ley No 20.120 (2006). Así, por ejemplo, en el artículo 2o, inciso primero, de la Ley No 19.970 (2004) se establece que los defensores penales podrán tener acceso a la información contenida en el Sistema Nacional de Registros de ADN, en el que se contiene la huella genética de personas vinculadas a causas criminales, previa autorización del tribunal respectivo.

106 Artículo 2º, inciso primero, de la Ley No 19.970 (2004).

107 Artículo 10 de la Ley No 19.628 (1999).

108 Artículo 13 de la Ley № 20.120 (2006), en relación con el artículo 20 de la Ley No 19.628 (1999).

109 Artículo 10 de la Ley No 19.628 (1999).

110 Artículo $4^{\circ}$, inciso primero, de la Ley No 20.120 (2006). 
dicho sistema pueda constituir base o fuente de discriminación o estigmatización de persona alguna ${ }^{111}$.

\subsection{Agencia de control}

El derecho chileno no cuenta con normas que establezcan una agencia pública que fiscalice el respeto del derecho a la privacidad de los datos personales en general ni de la información genética en particular.

\subsection{Principio de responsabilidad}

El principio de responsabilidad derivado de infracciones al derecho fundamental a la intimidad genética cuenta con diversas manifestaciones en el derecho chileno.

En efecto, y por una parte, la Ley No 20.120 (2006) hace penalmente responsable al que indebidamente vulnere la reserva de la información sobre el genoma humano y al que omitiere la encriptación de los datos genéticos exigida por la misma ley ${ }^{112}$. Por otra parte, sanciona con la suspensión por tres años del ejercicio profesional a quien desarrolle un proyecto de investigación científica biomédica en seres humanos o en su genoma, sin contar con las autorizaciones o consentimientos correspondientes. Esta sanción se transforma en la prohibición absoluta de ejercicio profesional en el territorio nacional en caso de reincidencia ${ }^{113}$.

La Ley No 19.628 (1999), por su parte, establece de manera expresa el derecho a la indemnización de los daños patrimonial y moral derivados del tratamiento indebido de datos personales. Esta obligación se aplica al responsable del banco de datos personales, sea que se trate de una persona natural o jurídica privada, sea que se trate de un organismo público ${ }^{114}$. Las mismas normas se aplican en el caso de tratamiento indebido de los datos contenidos en el Sistema Nacional de Registros de ADN regulado en la Ley No 19.970 (2004) ${ }^{115}$.

\footnotetext{
111 Artículo 2o, inciso segundo, de la Ley No 19.970 (2004).

112 Las sanciones penales consisten en penas privativas de libertad y multa, respectivamente, de conformidad con lo establecido en el artículo 18 de la Ley No 20.120 (2006).

113 Artículo 20 de la Ley No 20.120 (2006).

114 Artículo 23, inciso primero, de la Ley No 19.628 (1999).

115 Artículo 22 de la Ley No 19.970 (2004).
} 


\section{CONCLUSIONES}

El contraste entre la regulación ofrecida por el derecho internacional y el derecho comunitario, por una parte, y las normas contenidas en la legislación chilena, por otra, permiten formular una conclusión general y varias conclusiones específicas.

1. En efecto, y de manera general, lo más evidente es que Chile carece de una legislación específica para tutelar el derecho fundamental a la intimidad genética.

La Ley No 19.628 (1999), que tutela el derecho a la vida privada en lo relacionado con los datos personales, sin duda se relaciona con la privacidad en general y con la intimidad genética en particular. Sin embargo, la regulación que ofrece es general y antigua, de modo que no considera de manera expresa la información genética como una categoría de dato personal, ni contiene normas que la protejan en forma específica ${ }^{116}$.

Las Leyes No 19.970 (2004) y 20.120 (2006), por su parte, son demasiado específicas. La primera crea el Sistema Nacional de Registros de ADN y en esencia regula la conservación de un banco de huellas genéticas de personas vinculadas con casos penales. La segunda se refiere a la investigación científica en el ámbito genético y, por lo mismo, sus normas se orientan a regular dicha actividad.

La Ley No 20.584 (2012), por su parte, se refiere a los derechos y obligaciones de las personas en relación con su atención de salud. De ahí que solo una de sus normas haya podido ser mencionada en la presente investigación, por tener alguna relación con el derecho fundamental a la intimidad genética.

2. La legislación chilena carece de tres de los siete principios y mecanismos esenciales para la efectiva tutela del derecho fundamental a la intimidad genética.

En efecto, nada se dice sobre el principio de autonomía, seguramente uno de los pilares fundamentales en la construcción del derecho fundamental a la intimidad genética como un derecho de libertad del sujeto, de la familia y de los colectivos frente al Estado y frente a los demás particulares.

Tampoco se consideran mecanismos fundamentales como el asesor genético y la agencia de control de carácter público e independiente. El primero es esencial en la toma de decisiones relacionadas con el ámbito genético por parte de sus titulares. El segundo constituye un instrumento ineludible para la efectiva y especializada protección del derecho fundamental en análisis.

116 Como se dijo anteriormente, la Ley No 19.628 (1999) no considera la información genética entre los "datos sensibles" mencionados a modo de ejemplo en el artículo $2^{\circ}$, letra g). 
3. Otros tres de los siete principios y mecanismos de tutela del derecho fundamental a la intimidad genética presentan un desarrollo deficiente. Se trata del consentimiento, la confidencialidad y la responsabilidad.

3.1. En cuanto al consentimiento, es necesario hacer ciertas distinciones.

El derecho chileno se encuentra en sintonía con los derechos internacional y comunitario en cuanto a la necesidad de consentimiento. Lo mismo se debe decir respecto de las excepciones a la exigencia de consentimiento: tanto el derecho de referencia como el derecho nacional cuentan con cláusulas normativas generales.

Las deficiencias se observan en los otros dos aspectos. El derecho chileno presenta los mismos requisitos que los derechos internacional y comunitario, aunque omite que el consentimiento sea específico. En cuanto a la revocación del consentimiento, la coincidencia es perfecta. El problema es que estas regulaciones solo se aplican en el contexto de investigaciones científicas y no de manera general. Por tanto, no hay regulación respecto de los requisitos o revocación del consentimiento en ámbitos distintos de la investigación científica.

3.2. Respecto del principio de confidencialidad, también es necesario introducir algunas distinciones.

El derecho chileno establece la reserva de la información genética, al igual que los derechos internacional y comunitario. Sin embargo, limita esta obligación a la información obtenida en el contexto de investigaciones científicas y a la que se encuentra en el Sistema Nacional de Registros de ADN, de modo que el ordenamiento no lo exige de manera general.

La distancia entre el derecho de referencia y el derecho nacional es importante en lo relativo a las consecuencias del principio de reserva. Ninguna de las cuatro consecuencias contempladas en los derechos internacional y comunitario se recogen en la legislación chilena. Con todo, la exigencia del derecho interno de encriptación y la prohibición de tratamiento de los datos genéticos son valiosos. No se puede decir lo mismo de la deficiente regulación de la eliminación de tales datos.

Dos de las tres excepciones a la exigencia de reserva establecidas por el estándar de referencia se encuentran en el derecho chileno: el consentimiento y la acción de la justicia. La legislación nacional, no obstante, incluye otras tres excepciones extremadamente amplias y riesgosas para el efectivo disfrute del derecho fundamental a la intimidad genética: para el otorgamiento de beneficios de salud, cuando lo disponga la ley y, el que parece menos admisible, en todos los casos cuando se trate de organismos públicos en el cumplimiento de sus tareas. 
3.3. En cuanto al principio de responsabilidad, también se encuentran luces y sombras.

El derecho chileno presenta, aparentemente, la misma cobertura que los derechos internacional y comunitario en relación con dicho principio. En efecto, la Ley No 19.628 establece la responsabilidad por todo tratamiento de datos personales fuera de los casos establecidos por dicha ley.

El problema, sin embargo, no se encuentra en esta acertada cláusula general, sino en la deficiente regulación nacional de los demás principios destinados a tutelar el derecho a la intimidad genética: la autonomía, el consentimiento y la reserva. Los defectos en estas materias permiten intromisiones que impiden generar la responsabilidad de quien afecta aquel derecho fundamental. Así ocurre, por ejemplo, a partir de las amplias cláusulas de excepción al principio de reserva establecidas por la legislación chilena.

4. El único principio que se encuentra adecuadamente establecido en el derecho chileno, en relación con el estándar establecido por los derechos internacional y comunitario, es el de no discriminación. En efecto, la Ley No 20.120 prohíbe toda discriminación basada en el patrimonio genético de la persona.

5. En definitiva, el derecho chileno presenta importantes vacíos y significativas deficiencias en la efectiva tutela del derecho a la intimidad genética, si se lo compara con el estándar establecido por el derecho internacional y por el derecho comunitario. Esta situación evidencia la urgente necesidad de una legislación que de manera íntegra y específica asegure una robusta protección de este derecho que, de un lado, tiene jerarquía iusfundamental y, de otro lado, excede ampliamente el plano puramente individual, favoreciendo a personas, familias y colectivos.

\section{BibLIOGRAFÍA}

\section{Libros y CAPÍTULOS DE LIBROS}

Alberts, Bruce; Johnson, Alexander; Lewis, Julian; Raff, Martin; Roberts, Keith, y Walter, Peter (2010): Biología molecular de la célula, quinta edición (Traducc.

Mercé Durforti Coll y Miquel Llobera i Sande, Barcelona, Ediciones Omega). Alexy, Robert (2001): Teoría de los derechos fundamentales. (Traducc. de Ernesto Garzón Valdés, Madrid, Centro de Estudios Políticos y Constitucionales). BERGEL, Salvador (2018): "La información genética humana ante el derecho", en Bergel, Salvador y Martínez, Roberto (Coordinadores). Industria farmacéutica, derecho a la salud y propiedad intelectual: El reto del equilibrio. (México D.F. 
UNAM), pp. 87-117, [fecha de consulta: 10 de diciembre de 2018]. [Disponible en: https://archivos.juridicas.unam.mx/www/bjv/libros/10/4740/8.pdf]. Bronfman Vargas, Alan; Martínez Estay, José Ignacio, y Núñez Poblete, Manuel (2012): Constitución Política comentada (Santiago de Chile, Abeledo Perrot). CASADO, María (2014): "Reflexiones bioético-jurídicas sobre el uso de muestras, perfiles, datos y bandos de ADN", en Casado, María, y Guillén, Margarita (Coord.), ADN forense: Problemas éticos y jurídicos (Universitat de Barcelona, Observatori de Bioética i Dret, España), pp. 13-24, [fecha de consulta: 19 de octubre de 2017]. [Disponible en http://diposit.ub.edu/dspace/handle/2445/115987].

EvANS DE LA CUADRA, Enrique (1999): Los derechos constitucionales, segunda edición (Santiago de Chile, Jurídica de Chile), tomo I.

Klug, William S.; Cummings, Michael R., y Spencer, Charlotte A. (2006): Conceptos de genética, octava edición (Traducc. José Luis Ménsua y David Bueno i Torrens, Madrid, Prentice Hall).

Molina Guaita, Hernán (2006): Derecho constitucional, sexta edición (Santiago de Chile, LexisNexis).

Pierce, Benjamín (2006): Genética: Un enfoque conceptual, segunda edición (Buenos Aires, Ediciones Médica Panamericana).

Ríos LabBé, Sebastián (2003): La protección civil del derecho a la intimidad (Santiago de Chile, LexisNexis).

Silva Bascuñán, Alejandro (2006): Tratado de derecho constitucional, segunda edición (Santiago de Chile, Jurídica de Chile), tomo XI.

SOlARI, Alberto Juan (2004): Genética humana: fundamentos y aplicaciones en medicina, tercera edición (Buenos Aires, Editorial Médica Panamericana).

SuÁrez Espino, María Lidia (2008): El derecho a la intimidad genética, (Madrid, Editorial Marcial Pons).

\section{ARTí́CULOS DE REVISTAS}

Álvarez, Susana (2017): "La protección del derecho a la intimidad en la toma de muestras de ADN a fines de investigación penal", en Ius et Scientia (Vol. 3, No 1), pp. 48-62, [fecha de consulta: 3 de octubre de 2017]. [Disponible en: http://institucional.us.es/iusetscientia/index.php/ies/article/view/96/52].

Arellano Toledo, Wilma, y Ochoa Villicaña, Ana María (2013): "Derechos de privacidad e información en la sociedad de la información y en el entor- 
no TIC", en Revista Ius (Vol. 7, No 31, ene.-jun.), pp. 183-208, [fecha de consulta: 26 de enero de 2018]. [Disponible en: http://www.scielo.org.mx/ pdf/rius/v7n31/v7n31a10.pdfhttp://www.scielo.org.mx/pdf/rius/v7n31/ v7n31a10.pdf].

Becerra, Pablo (2013): "Potestades sancionatorias en el Proyecto de Reforma a la Ley No 19.628 de Protección de Datos Personales. Una crítica”, en Revista de Derecho, Escuela de Postgrado, Universidad de Chile, Chile (No 3), pp. 163192, [fecha de consulta: 3 de octubre de 2017]. [Disponible en: https:// app.vlex.com/\#CL/search/jurisdiction:CL/autodeterminacion+informativa/ CL/vid/643501725].

Brena Sesma, Irma (2008): "Privacidad y confidencialidad de los datos genéticos", en Boletín Mexicano de Derecho Comparado (número conmemorativo), pp. 109-125, [fecha de consulta: 20 de septiembre de 2017]. [Disponible en: https://revistas.juridicas.unam.mx/index.php/derecho-comparado/article/ view/4050/5189].

Caruso, Viviana (2012): "Bases de datos policiales sobre identificadores obtenidos a partir del $\mathrm{ADN}$ y derecho a la intimidad genética”, en Foro (Nueva Época), Universidad Complutense de Madrid (Vol. 15, No 1), pp. 135-167, [fecha de consulta: 4 de octubre de 2017]. [Disponible en: http://revistas.ucm.es/ index.php/FORO/article/view/39585/38092].

Figueroa G., Rodolfo (2013): "El derecho a la privacidad en la jurisdicción de protección”, en Revista Chilena de Derecho (Vol. 40, No 3), pp. 859-889. [fecha de consulta: 25 de enero de 2018]. [Disponible en: https://scielo.conicyt.cl/ pdf/rchilder/v40n3/art05.pdf].

FigueroA YÁÑEZ, Gonzalo (2003): "La bioética en Latinoamérica", en Revista Derecho y Genoma Humano, Fundación BBVA, Diputación Foral de Bizkaia, España, No 18, pp. 55-76.

Gómez, Ana (2010): "Principios éticos y jurídicos del derecho genético en las declaraciones internacionales relacionadas con las intervenciones sobre el genoma humano", en Vniversitas, Universidad Javeriana, Colombia (No 120), pp. 141-168, [fecha de consulta: 13 de mayo de 2017]. [Disponible en: http:// www.scielo.org.co/pdf/vniv/n120/n120a07.pdf].

Gómez, Yolanda (2008): "La protección de los datos genéticos: El derecho a la autodeterminación informativa”, en Derecho y Salud (Vol. 16, número extra, XVI Congreso), pp. 59-78, [fecha de consulta: 1 de octubre de 2017]. [Disponible en: http://www.ajs.es/revista-derecho-y-salud/volumen-16-extra-2008]. 
Herrera Carpintero, Paloma (2016): "El derecho a la vida privada y las redes sociales en Chile", en Revista Chilena de Derecho y Tecnología (Vol. 5, No 1), pp. 87-212, [fecha de consulta: 26 de enero de 2018]. [Disponible en: https:// scielo.conicyt.cl/pdf/rchdt/v5n1/art03.pdf].

Malem, Jorge (1995): "Privacidad y mapa genético", en Isonomía, (No 2, abril), pp. 159-183, [fecha de consulta: 24 de diciembre de 2007]. [Disponible en: www.cervantesvirtual.com/servlet/SirveObras/01361653102351832977024/ isonomia02/isonomia02_11.pdf].

Margarit, Sonia (2017) “¿Qué es el asesoramiento genético y cómo realizarlo en oncología?”, en Revista de Medicina Clínica Las Condes (Vol. 28, No 4), pp. 524-530 [fecha de consulta: 10 de noviembre de 2017]. [Disponible en: http://www.sciencedirect.com/science/article/pii/S0716864017300949].

McPherson, Elizabeth (2006): "Genetic Diagnosis and Testing in Clinical Practice", en Clinical Medicine y Research, Marshfield Clinic Research Foundation, No 2, pp. 123-129, [fecha de consulta: 18 de octubre de 2017]. [Disponible en: https:/www.ncbi.nlm.nih.gov/pmc/articles/PMC1483893/pdf/0040123. pdf].

Nogueira Alcalá, Humberto (2007): "El derecho a la propia imagen como derecho fundamental implícito. Fundamentación y caracterización”, en Ius et Praxis (vol. 13, No 2), pp. 245-285, [fecha de consulta: 24 de enero de 2018]. [Disponible en: https://scielo.conicyt.cl/pdf/iusetp/v13n2/art11.pdf]. Quispe Remón, Florabel (2010): "Ius cogens en el Sistema Interamericano: Su relación con el debido proceso", en Revista de Derecho, Universidad del Norte (No 34), pp. 42-78, [fecha de consulta: 28 de febrero de 2018]. [Disponible en: http://www.scielo.org.co/pdf/dere/n34/n34a04.pdf].

Ruiz Miguel, Carlos (2001): "La nueva frontera del derecho a la intimidad", en Revista Derecho y Genoma Humano, Fundación BBVA, Diputación Foral de Bizkaia, España (No 14), pp. 147-167, [fecha de consulta: 21 de septiembre de 2017]. [Disponible en: https://www.researchgate.net/publication/301358897_ La_nueva_frontera_del_derecho_a_la_intimidad].

Peces-Barba, Gregorio (1993): "La libertad del hombre y el genoma”, en Derechos y Libertades: Revista del Instituto Bartolomé de las Casas D y L, Universidad Carlos III, Madrid, España, No 2, año I (1993-1994), pp. 317 336, [fecha de consulta: 2 de octubre de 2017]. [Disponible en: https://earchivo.uc3m.es/bitstream/handle/10016/1462/DL-1993-I-2-Peces-Barba-. pdf?sequence $=4 \&$ isAllowed $=y]$. 
Sánchez UrRutia, Ana Victoria (2002): "Información genética, intimidad y discriminación”, en Acta Bioética (Vol. 8, No 2), [fecha de consulta: 24 de enero de 2018], pp. 255-262. [ Disponible en: https://scielo.conicyt.cl/pdf/ abioeth/v8n2/art07.pdf].

Velásquez ElizarRarás, Juan Carlos (2008): “El derecho internacional ante los desafíos del genoma humano y la bioética en el marco de la organización y las declaraciones internacionales. Su proyección al derecho mexicano", en Anuario Mexicano de Derecho Internacional (Vol. 8, enero 2008), pp. 441-483, [fecha de consulta: 27 de febrero de 2018]. [Disponible en: http://www.scielo.org. $\mathrm{mx} / \mathrm{pdf} / \mathrm{amdi} / \mathrm{v} 8 / \mathrm{v} 8 \mathrm{a} 11 . \mathrm{pdf}]$.

\section{NORMAS JURÍDiCAS CITADAS}

Carta de los Derechos Fundamentales de la Unión Europea (2016/C 202/02) (2016). [fecha de consulta: 6 de septiembre de 2017]. [Disponible en: http://eur-lex.europa.eu/legal-content/ES/TXT/PDF/?uri=CELEX:12016P/TXT\&from=ES].

Constitución Política de la República de Chile, cuyo texto refundido, coordinado y sistematizado fue fijado por el decreto 100, de 2005, del Ministerio Secretaría General de la Presidencia. Diario Oficial, 22 de septiembre de 2006, [fecha de consulta: 31 de julio de 2012]. [Disponible en: http://www.leychile.cl/Navega r?idNorma $=242302 \&$ idVersion $=2012.03 .06]$.

Convención Americana sobre Derechos Humanos, [fecha de consulta: 28 de septiembre de 2017]. [Disponible en: http://www.oas.org/juridico/spanish/ Tratados/b-32.html].

Declaración Universal de Bioética y Derechos Humanos (2005), [fecha de consulta: 12 de junio de 2017]. [Disponible en: http://unesdoc.unesco.org/ images/0014/001428/142825s.pdf\#page=85].

Declaración Internacional sobre los Datos Genéticos Humanos (2003), [fecha de consulta: 12 de junio de 2017]. [Disponible en: http://unesdoc.unesco.org/ images/0013/001331/133171s.pdf\#page $=47$ ].

Declaración Universal del Genoma Humano y los Derechos Humanos (1997), [fecha de consulta: 12 de junio de 2017]. [Disponible en: http://unesdoc.unesco.org/ images/0011/001102/110220s.pdf\#page=50].

Declaración Universal de Derechos Humanos (1948), [fecha de consulta: 28 de septiembre de 2007]. [Disponible en: http://www.un.org/es/documents/udhr/ index.shtml]. 
Decreto No 114, aprueba reglamento de la Ley No 20.120, sobre la investigación científica en el ser humano, su genoma, y prohíbe la clonación humana. Diario Oficial, 19 de noviembre de 2011, [fecha de consulta: 2 de enero de 2018]. [Disponible en: https://www.leychile.cl/Navegar?idNorma=1032919 \&idParte $=0$ \&idVersion $=$ ].

Ley No 19.628, sobre protección de la vida privada. Diario Oficial, 28 de agosto de 1999, [fecha de consulta: 2 de marzo de 2018]. [Disponible en: https:// www.leychile.cl/Navegar?idNorma=141599].

Ley No 19.970, crea el Sistema Nacional de Registros de ADN. Diario Oficial, 6 de octubre de 2004, [fecha de consulta: 5 de marzo de 2018]. [Disponible en: https://www.leychile.cl/Navegar?idNorma=231105].

Ley No 20.120, sobre la investigación científica en el ser humano, su genoma, y prohíbe la clonación humana. Diario Oficial, 22 de septiembre de 2006, [fecha de consulta: 2 de marzo de 2018]. [Disponible en: https://www.leychile. $\mathrm{cl} /$ Navegar?idNorma $=253478$.

Ley No 20.584, regula los derechos y deberes que tienen las personas en relación con acciones vinculadas a su atención en salud. Diario Oficial, 24 de octubre de 2012, [fecha de consulta: 2 de marzo de 2018]. [Disponible en: https:// www.leychile.cl/Navegar?idNorma=1039348].

Pacto Internacional de Derechos Civiles y Políticos (1966), [fecha de consulta: 28 de septiembre de 2007]. [Disponible en: http://www.unhchr.ch/spanish/ html/menu3/b/a_ccpr_sp.htm].

Reglamento No 2.016/679, de 27 de abril de 2016, de la Unión Europea, relativo a la protección de las personas físicas en lo que respecta al tratamiento de datos personales y a la libre circulación de estos datos (2016), [fecha de consulta: 6 de septiembre de 2017]. [Disponible en: http://eur-lex.europa.eu/ legal-content/ES/TXT/PDF/?uri=CELEX:32016R0679\&from=ES].

\section{JURISPRUDENCIA CITADA}

Requerimiento de inaplicabilidad por inconstitucionalidad presentado por Eduardo Becerra Márquez respecto del artículo 2331 del Código Civil, en la parte que indica, en los autos sobre indemnización de perjuicios, caratulados "Eduardo Antonio Becerra Márquez con Universidad de Valparaíso", de que conoce el Cuarto Juzgado Civil de Valparaiso, bajo el rol No C-4573-2011 (2014): Tribunal Constitucional, sentencia de 13 de mayo de 2014 (recurso de inaplicabilidad, 
rol 2454-2013), [fecha de consulta: 24 de enero de 2018]. [Disponible en: http://www.tribunalconstitucional.cl/ver.php?id=2971].

Corte Interamericana de Derechos Humanos, Opinión Consultiva OC 18/03, de 17 de septiembre de 2003, solicitada por los Estados Unidos Mexicanos, sobre la condición jurídica y derechos de los migrantes indocumentados, [fecha de consulta: 28 de febrero de 2018]. [Disponible en: http://www.corteidh.or.cr/ docs/opiniones/seriea_18_esp.pdf].

\section{OTROS DOCUMENTOS}

Consejo para la Transparencia, Unidad de Estudios y Publicaciones (2015): Protección de Datos Personales. Protección de Datos Personales en el Manejo de Datos de Investigación Realizado por Organismos Públicos, [fecha de consulta: 3 de septiembre de 2017]. [Disponible en: http://www.consejotransparencia. cl/consejo/site/artic/20121213/asocfile/20121213160518/proteccion_datos_final.pdf].

MiŇO, Verónica (2016): "El derecho a la intimidad de la información genética en el Derecho europeo". Tesis doctoral. Facultad de Derecho, Universidad de Sevilla, España, [fecha de consulta: 1 de octubre de 2017]. [Disponible en: https://idus.us.es/xmlui/handle/11441/38215].

Proyecto de Ley, Boletín 11.092-07 del Senado, fecha de ingreso: 17 de enero de 2017 (Sobre Protección de datos personales), [fecha de consulta: 23 de agosto de 2017]. [Disponible en: https://www.camara.cl/pley/pley_detalle.aspx?prm ID $=1$ 1608\&prmBoletin=1 1092-07] . 